九州大学学術情報リポジトリ

Kyushu University Institutional Repository

\title{
A Convenient Plotting Technique in Archibald Method
}

Hayashi, Katsuya

Laboratory of Biochemistry, Faculty of Agriculture, Kyushu University

Funatsu, Masaru

Laboratory of Biochemistry, Faculty of Agriculture, Kyushu University

https://doi.org/10.5109/22826

出版情報: 九州大学大学院農学研究院紀要. 17 (2)，pp.143-149，1973-03. Kyushu University バージョン：

権利関係 : 


\title{
A Convenient Plotting Technique in Archibald Method
}

\author{
Katsuya $\mathrm{H}$ ayashi and $\mathrm{M}$ asaru $\mathbf{F}$ unatsu \\ Laboratory of Biochemistry, Faculty of Agriculture, \\ Kyushu University, Fukuoka
}

(Received July 2, 1972)

\begin{abstract}
A convenient plotting method in the Archibald method generally adoptable for determining the molecular weight of proteins was developed. This method consists mainly of plotting of $1 / x \cdot(d n / d x)_{x t} v s$. $c_{x t}$, which is designed to read the exact slope, $1 / x c_{x} \cdot(d n)$ $d x)_{x}$, and to exclude an error arisen from the separate run with synthetic boundary cell necessary to estimate the initial concentration of the solute. The experimental results indicated that this convenient method provided the same accuracy for the determination of molecular weight as that of usual Archibald method, when the initial concentration of the solute was suitably assumed and used in the calculation of thr provisional or supposed concentation of the solute at any position in the cell of ultracentrifuge.
\end{abstract}

\section{INTRODUCTION}

Sedimentation equilibrium has long been recognized as one of the standard methods for the estimation of the molecular weight of biopolymer such as protein (Svedberg and Pedersen, 1940; Fujita, 1962). Many additional devices and methods have been investigated to overcome a disadvantage that much long time is needed to attain the true sedimentation equilibrium of the solute in a cell set up in the centrifugal field. Such studies may be classified into two categories; one is focused to an improvement of the sedimentation cell with a short column (Yphantis, 1947) and the other to detect theoretically the sedimentation state in the cell which can be treated similarly to that in true sedimentation equilibrium. In connection with the latter, Archibald (1947) had demonstrated an excellent method for the estimation of the molecular weight of proteins. His method was based upon the theoretical prediction that the solute can be regarded to be in an equilibrium-like state at meniscus or bottom of the cell independently of the centrifugation time, if the revolution of the rotor is suitably chosen to attain finally the equilibrium of the solute throughout the cell.

The Archibald method has a great advantage in that this method requires only a considerably short time for centrifugation. However, the precise estimation of the value of initial concentration of the solute, and the solute-concentration and concentration-gradient at the meniscus or bottom boundary have been thought to be necessary for the adoptation of this method. Usually, the initial concentration of solute has been estimated by use of a synthetic boundary cell in a separate run, and the concentration and concentration-gradient at the boundaries have deen determined by an extrapolating method. 
In the estimation of the initial concentration by the synthetic boundary cell, an insufficient dialysis of the solution and a perturbation of initial boundary formed between solution and solvent layers in the cell are referred to be a large source of an experimental error.

The present paper deals with a simple and convenient plotting method in the Archibald method, which does not require the measured value of the initial concentration, hence, does not need the use of the synthetic boundary cell in a separate run.

\section{THEORY}

When the sedimentation equilibrium was completed throughout the cell, the following equation may be established at any position, $x$ (distance from the center of rotation) in the cell of a ultracentrifuge. The first term represents the

$$
\omega^{2} x s c-D_{\partial}^{\partial c}=0
$$

solute amount sedimenting across the cross-section at $x$, and second term represents the counter-current arisen from the free diffusion of the solute. Where $\omega$ represents the angular velocity, $s$ is the sedimentation constant, c the concentration of the solute and $\mathrm{D}$ the diffusion constant. Molecular weight $\mathrm{M}$ relates with $\mathrm{s}$ and $\mathbf{D}$ according to the following equation

$$
s=\frac{M(1-\bar{v} \rho) D}{\mathbf{R} \mathbf{T}}
$$

where $\bar{v}$ is partial specific volume of solute and $\rho$ is the density of solvent. Combining equations (1) and (2), we obtain

$$
M=\frac{d c / d x}{c x} \cdot \frac{R T}{(1-\bar{v} \rho) \omega^{2}}
$$

In the case of the Archibald method, equation (3) holds only at meniscus $x_{M}$ and at bottom $x_{B}$ of the cell*. Equation (3) is rewritten for the Archibald method,

$$
M=\frac{(d c / d x)_{M}}{c_{M} x_{M}} \cdot \frac{R T}{(1-\bar{v} \rho) \omega^{2}}=\frac{(d c / d x)_{B}}{c_{B} x_{B}} \cdot \frac{\mathbf{R ~ T}}{(1-\bar{v} \rho) \omega^{2}}
$$

where suffixes $\mathbf{M}$ and $\mathbf{B}$ indicate the meniscus and bottom of the cell.

For the calculation of molecular weight from experimental data using equation (4), it is absolutely necessary to estimate $c_{M}$ and $c_{B}$. When plateau region, $X$, still remained in a middle of the cell in regard to the concentration-gradient, $c_{M}$ and $c_{B}$ can be calculated by equations (5) and (6), respectively.

: In true equilibrium state, $\mathbf{d c} / \mathbf{d x}, \mathbf{c}$ or $d c / d x / c$ at any $\mathrm{x}$-value is constant independently of time, and $\frac{d c / d x}{c x}$ will be constant for all $x$-value independently of time. However, it should be noted that under the Archibald condition, only the value of $\frac{d c / d x}{c x}$ at meniscus or bottom is held constant independently of running time, but not at another $\mathrm{x}$-values. 


$$
\begin{aligned}
& c_{U}=c_{0}-\frac{1}{x_{M}^{2}} \int_{x_{M}}^{X} x^{2} d x d x \\
& c_{B}=c_{0}+\frac{1}{x_{B}^{2}} \int_{X}^{x_{B}} x^{2} \frac{d c}{d x} d x
\end{aligned}
$$

where $c_{0}$ represents the initial concentration, and $d c / d x=0$ at $\mathrm{X}$. The initial concentration $c$, , is calculated from the experimental data with the synthetic boundary cell using equation (7).

$$
c_{0}=\int_{x_{2}}^{x_{1}} \frac{d c}{d x} d x
$$

$\mathrm{X}$, and $X_{2}$ show the x-values of both boders of boundary, where $d c / d x$ drops to zero. Thus, it is necessary to run the separate experiment for obtaining the $c_{i}$-value.

When the terms $\frac{(d c / d x)_{\underline{H}}}{x_{M S}}$ and $\frac{(d c / d x)_{B}}{x_{B}}$ are measured at two different times, $t_{1}$ and $t$, we obtain equations (8) and (9).

$$
\begin{gathered}
\frac{(d c / d x)_{M t 1}}{x_{M}}-\frac{(d c / d x)_{M t 2}}{x_{H}}=\left(c_{M t 1}-c_{M t 2}\right) \frac{(1-\bar{v} \rho) \omega^{2} M}{R T} \\
M=\frac{(d c / d x)_{M+1}}{x_{M}} \frac{(d c / d x)_{M t 2}}{x_{M}} \cdot \frac{R T}{(1-\bar{v} \rho) \omega^{2}}
\end{gathered}
$$

and similarly,

$$
\begin{gathered}
M=\frac{\frac{(d c / d x)_{B t 2}}{x_{B}}-\frac{(d c / d x)_{B t 1}}{x_{B}} \cdot \frac{R T}{(1-\bar{v} \rho) \omega^{2}}}{\Delta c_{B}} \\
\Delta c_{M}=c_{H t 1}-c_{M t 2,} \Delta c_{B}=c_{B t 2}-c_{B t 1 .} .
\end{gathered}
$$

Since, in equations (8) and (9), we need to know only the difference in the solute concentrations, $A c$, but not the absolute values of the solute concentration. Equations (5) and (6) may threfore be replaced by following equations;

$$
\begin{aligned}
& c_{M t n}=Y-\frac{1}{x_{i h}^{2}} \int_{X}^{x_{M}} x^{2} \frac{d c}{d x} d x \\
& c_{B t n}=Y+\frac{1}{x_{B}^{2}} \int_{x_{B}}^{X} x^{2} \frac{d c}{d x} d x
\end{aligned}
$$

where suffix $n$ is $1,2, \cdots$ and $\mathrm{Y}$ is an arbitrary round -number. It is preferable to choose the Y-value larger than the real $c_{v}$-value. In practical, $\frac{d, i d v}{x}$ and newly defined c by equations (8)-(11) should be calculated at several x-values to obtain more precise value of molecular weight by use of equations (8) and (9), similarly to the usual Archibald method. 


\section{EXPERIMENTAL}

Materials : Hen's egg white lysozyme was five-times recrystallized and lyophilized preparation.

Ultracentrifugation: For the Archibald method, 12-mm standard cell was filled with $0.4 \mathrm{ml}$ of a silicon oil and $\mathbf{0 . 3} \mathrm{ml}$ of protein solution, and centrifuged at 13410 or $20410 \mathrm{rpm}$ and $20^{\circ} \mathrm{C}$ for $3-4 \mathrm{hr}$ using a Spinco Model E Ultracentrifuge. Protein was dissolved in $0.1 \mathrm{M}$ phosphate buffer, pH 6.8 to about $1 \%$. For determination of initial concentration, a synthetic boundary cell was used and the boundary was formed at the same revolution as that in the sedimentation run.

Calculation : Photographic pattern of the boundary was enlarged about 5 times and traced on section-paper. Pattern traced was divided in $0.25 \mathrm{~cm}$ units along $\mathrm{x}$-axis, and $d \boldsymbol{d} / d x$ (height of pattern and a quantity proportional linearly to $d c / d x$ ) was read at each point. The $x$-values were corrected to the real value in the cell by dividing with the magnification of camera lenses. Partial specific volume of lysozyme was assumed to be 0.70 . For usual Archibald method, analysis of the experimental data was carried out according to the original report. First, $d n / d x$ was measured at each $\mathrm{x}$-value, and the solute concentration at each $\mathrm{x}$-value was calculated according to equations (5) and (6) with changing $\boldsymbol{c}_{M}$ and $c_{B}$ to $c_{x}$, and $x_{M}$ or $x_{B}$ in the integrals to $\mathrm{x}$. Then $\frac{(d n / d x)_{x}}{c_{x} x}$ was plotted against $\mathrm{x} \cdot \frac{(d n / d x)_{M}}{c_{M} x}$ and $\frac{(d n / d x)_{B}}{c_{B} x_{B}}$ were obtained as an extrapolated value on meniscus and bottom, respectively. The molecular weight was calculated by equation (4).

For new plotting method, first, $\frac{(d n / d x)_{x t}}{x}$ was plotted against $c_{x t}$, that is calculated by equations (10) and (11) with changing $c_{M t n}$ or $c_{B t n}$ to $c_{x t}$, and $x_{M}$ or $x_{B}$ to $\mathrm{x}$. In this plotting, points at the same $\mathrm{x}$-value were connected by suitable line and the slopes of lines were read. Thus obtained slopes were again plotted against $\mathrm{x}$-value in arbitrary units and extrapolated to $x_{U}$ or $x_{B}$. The extrapolated values are

$$
\frac{\frac{(d n / d x)_{M t 1}-(d n / d x)_{M t 2}}{x_{M}}}{\Delta c_{M H}}
$$

and

$$
\frac{\frac{(d n / d x)_{B t 2}}{x_{B}}-\frac{(d n / d x)_{B t 1}}{x_{B}}}{\Delta c_{B}}
$$

These values were used for the calculation of the molecular weight by equations (8) and (9).

\section{RESULTS AND DISCUSSION}

One per cent lysozyme solution was centrifuged at low revolution and sedi- 


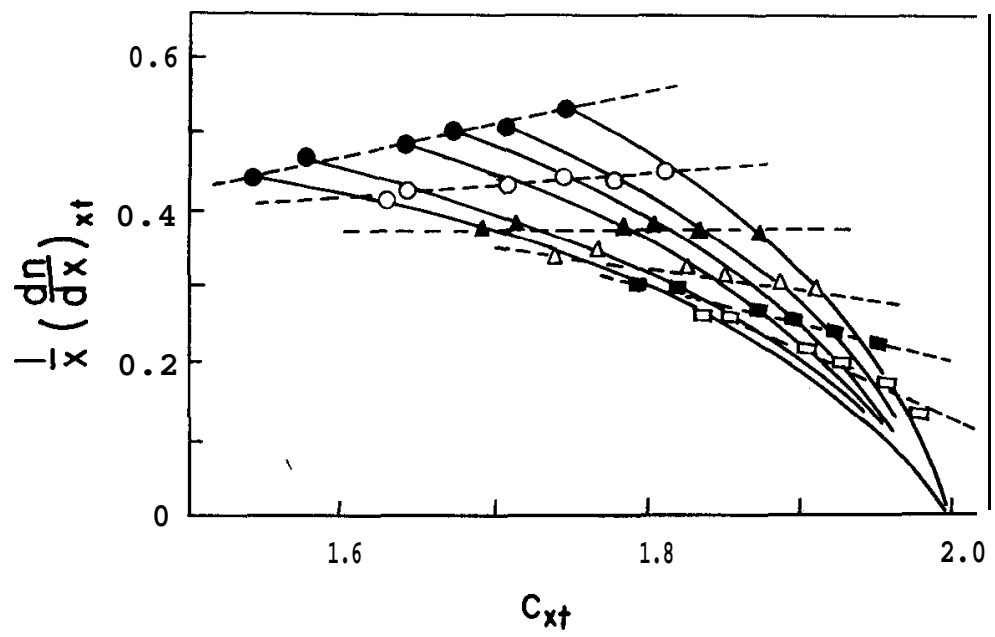

Fig. 1. Plotting of $\frac{1}{x}\left(\frac{d n}{d x}\right)_{x . t}$ vs. $c_{x t}$ in meniscus side Solid line represents the plot drawn for each traced pattern.

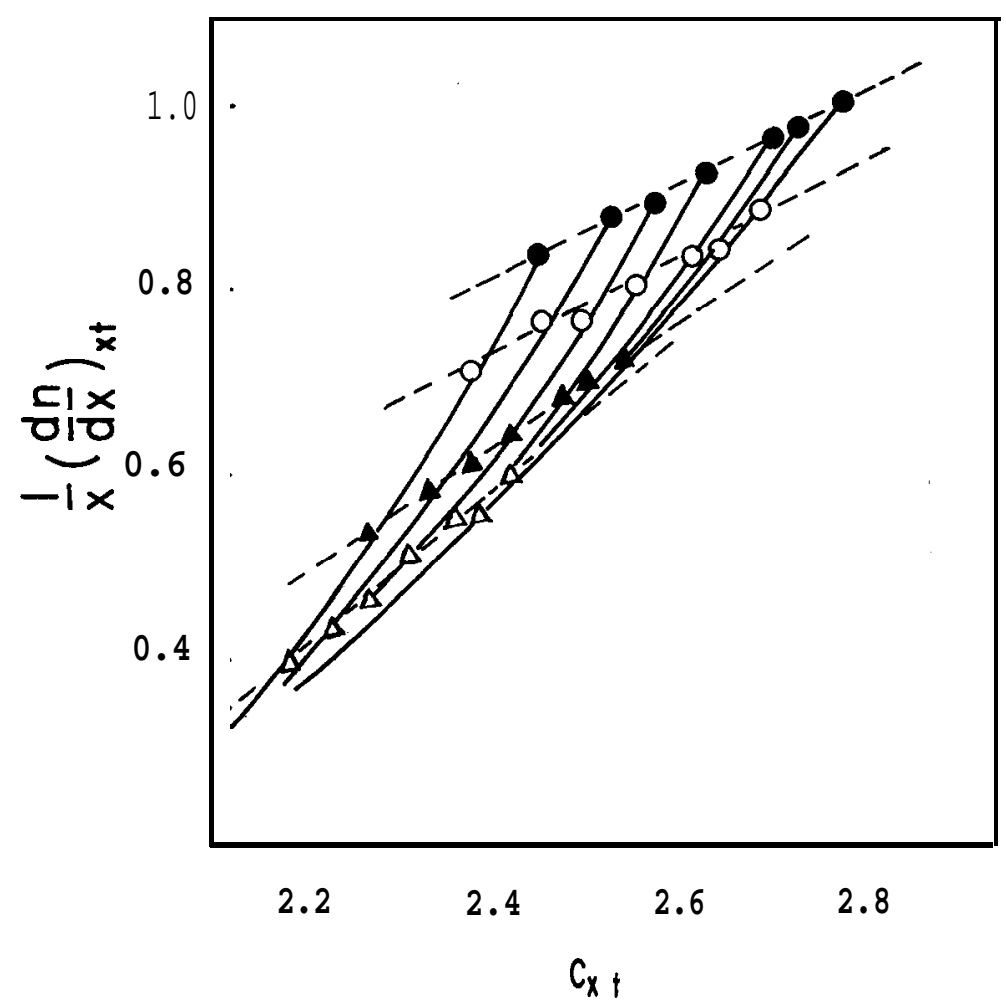

Fig. 2. Plotting of $\frac{1}{x}\left(\frac{d n}{d x}\right)_{x, t}$ vs. $c_{x t}$ in bottom side. 


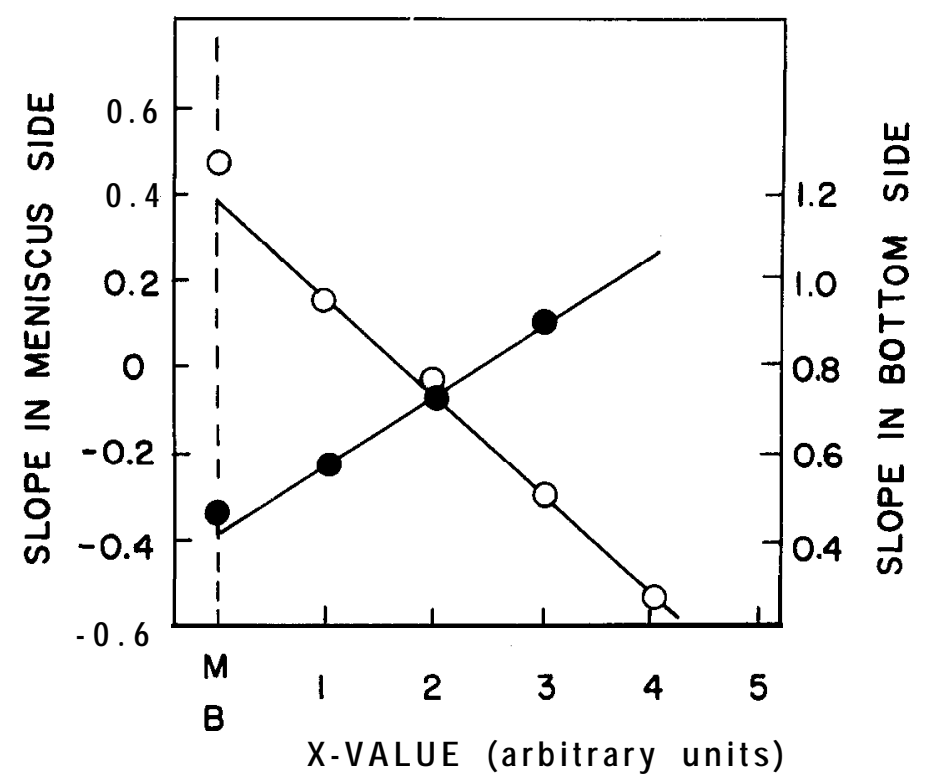

Fig. 3. Plotting of slope vs. $x$. The slope was calculated from dotted lines in Figs. 1 and 2 . The x-values are represented by arbitrary units. $M$ and $B$ represent the $\mathrm{x}$-values of meniscus and bottom. The extrapolated values were used forcalculation of molecular weight. $\mathrm{O}$ : Meniscus side. Bottom side.

Table 1. Molecular weight of lysozyme determined by Archibald method.

\begin{tabular}{|c|c|c|c|}
\hline \multicolumn{2}{|c|}{ Method } & $1 / c x \cdot d n / d x$ & $\begin{array}{l}\text { Molecular } \\
\text { weight }\end{array}$ \\
\hline Usual method & $\begin{array}{l}\text { Meniscus } \\
\text { Bottom }\end{array}$ & $\begin{array}{l}0.415 \\
0.410\end{array}$ & $\begin{array}{l}15700 \\
15590\end{array}$ \\
\hline $\begin{array}{l}\text { Convenient } \\
\text { plotting method }\end{array}$ & $\begin{array}{l}\text { Meniscus } \\
\text { Bottom }\end{array}$ & $\begin{array}{l}0.390 \\
0.410\end{array}$ & $\begin{array}{l}14820 \\
15590\end{array}$ \\
\hline Literatu & & & 14300 \\
\hline
\end{tabular}

mentation boundaries were photographed at intervals of 16 min after 20 min from the constant revolution. Photographic plate was enlarged 4.96 times and traced on section-paper. The x-value of traced pattern was corrected by a factor, $1 /(4.96 \times 2.17)$, to the real value of the cell, where 2.17 is magnification of camera lens in the machine. The $\mathrm{y}$-axis (height of pattern, $d n / d x$ ) was directly read without making any correction. The concentration at each $\mathrm{x}$-value at time $t$ was calculated from equations (10) and (11) with choosing $Y=2$.

The plotting of ${ }_{\mathrm{x}}{ }^{1}\left(\frac{\left.d n^{-}\right)}{d x}{ }_{x t}\right.$ vs. $c_{x t}$ is shown in Fig. 1 . The straight line covering all points at the same x-value was drawn and the slopes of lines were read. Uppermost dotted line connects the values at meniscus. The slopes decreased gradually as $\mathrm{x}$-value is apart from the meniscus. The similar plotting was done for bottom-side, and the slopes were read. The slope increased as x-value be- 
comes smaller than that of bottom, as shown in Fig. 2.

Fig. 3 shows the plotting of slope vs. x-value in arbitrary units. Extrapolated values of slopes should be used for the calculation of molecular weight. The slopes obtained at meniscus and bottom should be of the same value, if the sample protein is completely homogeneous.

As can be seen in the figures, the values of slope read directly from Figs. 1 and 2 are slightly different from those obtained by extrapolation.

For comparison, the molecular weights obtained by the usual method and the new plotting method are listed in Table 1. The molecular weight of lysozyme calculated from amino acid composition is known to be 14300 (Canfield, 1963, 1965). The Archibald method gave a little larger value for the molecular weight. However, it is well known that lysozyme at a high concentration above $1 \%$ exhibited an association in solution. It is therefore reasonable value obtained by the present experiment, because the present experiment was carried out at the concentration of about $1 \%$.

As shown in Table 1, the new plotting method gave a satisfactory and reasonable value for the molecular weight of lysozyme. The new method may be applicable as convenient one for the determination of molecular weight of proteins by the Archibald method.

\section{REFERENCES}

Archibald, W. J. 1917 A Demonstration of Some New Methods of Determining Molecular Weights from the Data of the Ultracentrifuge. J. Phys. Chem., 51: 1204-1214

Canfield, R. E. 3.963 The Amino Acid Sequence of Egg White Lysozyme. J. Biol. Chem., 238: 2698-2707

Canfield, R. E. 1965 The Disulfide Bonds of Egg White Lysozyme. J. Biol.Chem., 240: 19972002

I ujita, II. 1962 Mathematical Theory of Sedimentation Analysis. Academic Press, New York Svedberg, T. and K. 0. Pedersen, 1940 The Ultracentrifuge. Oxford Press, London

Yphantis, D. A. 3964 Equilibrium Ultracentrifugation of Dilute Solutions. Biochemistry, 3: $297-317$ 